\title{
Towards a convivial tool for narrative assessment: Adapting MAIN to Gondi (Dantewada, India), Halbi and Hindi for Gondi- and Halbi-Hindi speaking bilinguals
}

\author{
Uma Maheshwari Chimirala \\ NALSAR University of Law, Hyderabad
}

This paper presents the adaptation of MAIN to Gondi (Dantewada), Halbi and Hindi for Gondi-Hindi and Halbi-Hindi bilinguals. The Gondi and Halbi communities and the context in which Gondi-Hindi and Halbi-Hindi bilingual children are growing up are described, and the adaptation process is outlined together with its theoretical underpinnings. Finally, results from a study of 54 Halbi-Hindi bilinguals from Grade 3 (Mean age $=8.5$ years), Grade 5 (Mean age $=10.9$ years) and Grade 7 (Mean age $=12.9$ years) are presented. The results showed that, for the macrostructure of Grade 3 and Grade 5, L1 retelling was significantly better than L2 retelling, though this pattern was not found in Grade 7 where the performance was at the same level across languages for retelling. Narrative macrostructure was consistently higher in tellings than in the retellings regardless of languages and grades.

\section{Introduction}

The Language Impairment Testing in Multilingual Settings-Multilingual Assessment Instrument for Narratives (LITMUS-MAIN, henceforth MAIN; Gagarina et al., 2012, 2019) was initially developed for children aged 4 to 10 in order to differentiate and assess narrative production and comprehension trajectories of two distinct but overlapping groups of children: bilingual children and children with Developmental Language Disorder (DLD). In recent studies, MAIN has also been used with older children, adolescents and adults. Such expansions indicate the robustness of the tool across contexts, participants and research interests. Research on narratives acknowledges the complex nexus of variables that impact narrative production (and comprehension). Previous studies have investigated the impact of several variables such as age (Aldrich et al., 2011), exposure (Pearson, 2002), formal learning opportunities (Severing \& Verhoeven, 2001; Schwartz \& Shaul, 2013), language-specific communicational opportunities, language learning and language-based learning in school (Schwartz and Shaul, 2013) on monolingual and bilingual narration. Yet, not enough attention has been paid to the effects of language policy-planning and management initiatives which perpetuate the dominant 
language (in L2; at the cost of L1) in the clinical and pedagogic spaces (Laakso, Sahimaa, Akermark, \& Toivanen, 2016). Consequently, two primary concerns necessitate the adaptation of MAIN to Gondi and Halbi (two indigenous languages) and Hindi (the official language of India) spoken in the district of Dantewada in the State of Chhattisgarh, India (see Figure 1 below in Section 2). First, the specific context of the district of Dantewada operationalizes a residential education planning that aspires to early exposure to the L2 Hindi as the medium of instruction from Grade 1 onwards. The residential arrangement, where the child lives in the school except for during vacation and school-breaks, impacts the child's community engagement and familial interactions which means that child's home language development is not supported at school and through family interactions. It is possible that the child's L1 and L2 development may not be age appropriate. As a result, typically-developing bilingual children run the risk of being diagnosed with DLD. Second, while in the literature (e.g. ArmonLotem, De Jong \& Meir, 2015), there are intensive discussions on over-diagnoses and underdiagnosis of DLD in bilingual and atypically developing monolingual and bilingual children, there is little discussion or even awareness of DLD specifically with indigenous children. Exacerbating the situation is the general lack of culturally-appropriate and monolingually unbiased instruments (Mohanty \& Perragaux, 1996) especially in the case of Gondi and Halbi children. This attempt to adapt MAIN to these languages begins to address these issues.

This paper is organized as follows. Section 2 introduces the Gond and the Halaba communities, speaking Gondi and Halbi, respectively. Section 3 describes the educational context of children belonging to these communities. Section 4 discusses the theoretical considerations that guided the work with the adaptations. Section 5 gives an overview of the adaptation process. Section 6 presents the results for macrostructure in narratives elicited in both language from Halbi-Hindi bilinguals. Finally, Section 7 contains the conclusions.

\section{$2 \quad$ Knowing the two communities}

Chhattisgarh, located in the central-east of India (see Figure 1) is known for its rich natural resources (coal, iron ore mines, rives, forest and fertile lands) as well as its ITM $^{1}$ population, culture and languages. As the meeting point of two big language families (Indo-Aryan and Dravidian), Chhattisgarh has a rich linguistic tradition with Hindi and Chhattisgarhi as the official languages of the State in addition to several tribal languages like Parji, Dorli, Dandami, Maria, Jhoria, Raj Gondi, and Dhurvi. In the district of Dantewada, which is to the south of the State (see Figure 1), Gondi (Dantewada) and Halbi are predominantly spoken.

\footnotetext{
${ }^{1}$ ITM stands for Indigenous, Tribal, Minority and Minoritized communities. In this study, we adopt the understanding of ITM as conceptualized by Tove Skutnabb-Kangas, Robert Phillipson and Robert Dunbar in their writings but specifically in the Nunavut Report (2019). The authors argue that naming, recognizing and perpetuating a community as ITM in itself involves violence and is a manifestation of power-wielding institutional structures of the supra-national organizations and nations. In this paper, we are working with the Gond (Dantewada) and Halaba tribes of Chhattisgarh, India.
} 


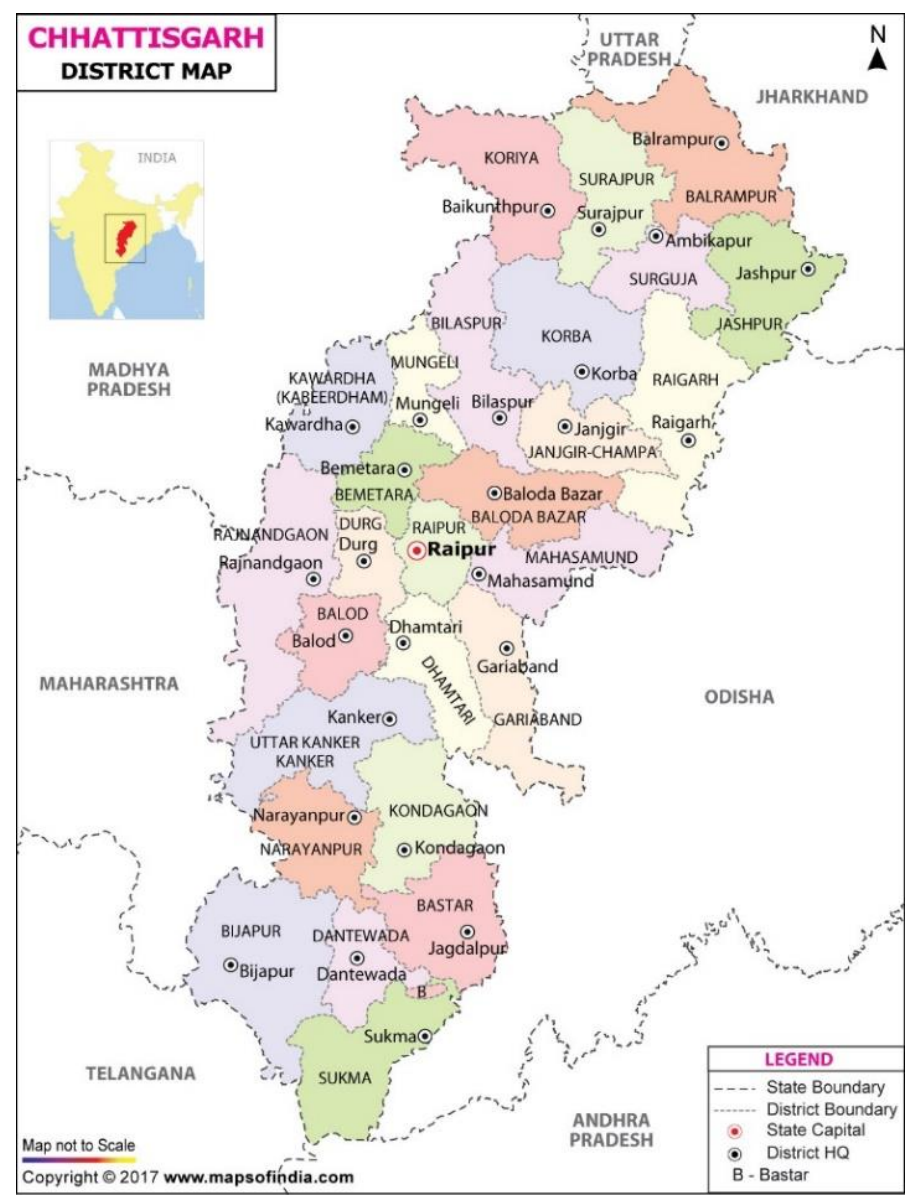

Figure 1. Map of the districts of the State Chhattisgarh including its location in India. (C2017, www.mapsofindia.com. Reprinted with permission.

\subsection{The Gond Community}

Though a precise history of the Gond tribe prior to 890 AD is elusive, several scholars make connections between the Gond and their mentions in texts as old as the Rig Veda (Guruge, 1991). Anthropological, sociological and historical documentation traces Gond tribes back to pre-Mughal periods, i.e. $1300 \mathrm{AD}$, when large stretches of Central India were ruled by the Gonds, the Gondwana territory, according to historian Deogaonkar (2007). Gonds reside in Central India, across the states of Madhya Pradesh, Gujarat, Telangana, Maharashtra, Chhattisgarh and Andhra Pradesh, West Bengal, Odisha, Jharkhand, Uttaranchal and Bihar amounting to $11,333,469$ in population (Census 2011; though chiefly in the first six state), forming $13.6 \%$ of the total scheduled tribes population of India. This also explains the occurrence of several dialects of Gondi (six according to Ethnologue). Census (2011) documents about 2,233,649 speakers of Gondi of which $65.31 \%$ are bilingual and $7.6 \%$ are trilingual. Given that the Gonds live in different States and are the subjects of the States' ideological policies, many of them are in a process of language shift (Guha \& Gadgil, 1997), a fact that cannot be missed if one compares the number of Gonds with the number of Gondi speakers. 
The Halaba tribe lives in one of the most linguistically and ethnically diverse junctions in India where the two largest language families of India, the Indo-Aryan and the Dravidian, meet in the district of Bastar. In this district, 53\% of the population speaks Halbi (Natarajan, 2001). The Halabas take pride in their history as soldiers and bodyguards to the Bastar Kings (from about 13th century AD) as documented by the historian Shukla (1982: 79). They enjoyed special land rights and thus a reasonable dominance in the area amongst other tribes. However, contemporary Halaba, like the other indigenous communities in the area, are grappling with a rapid language shift (Mohanty, 2018). Census (2011) documents 766,706 speakers of Halbi across four states with the largest being in Chhattisgarh. As a tribe, the Halaba are spread across different districts of Chhattisgarh such as Bastar, Dantewada and Bijapur and thus has dialectical variations. Within the State of Chhattisgarh, the Halbi language is claimed to be largely intelligible across the districts of Dantewada and its neighbouring district, Bastar.

\section{The educational context of ITM children in Dantewada}

Exclusive residential schools for the ITM children are called Potacabin schools. ${ }^{2}$ Children from the ITM communities are admitted into Grade 1 of these fully-residential schools when they are as young as 5-6 years old and visit their families during school-breaks and vacations. Hindi is the medium of instruction in these schools and the curriculum prioritizes literacy development in Hindi for which the L1 is seen as a 'gloss' (John, 2017). Within this educational space, the State has adopted the following initiatives which aim to ensure the child's comfort by promoting the ITM languages (John, 2017):

1) Multilingual textbooks for Grades 3-5 with lessons in Hindi, Gondi, and Sanskrit (with glossaries in Halbi, Chhattisgarhi, Surgujia, Kudukh, Gondi of Kanker district and Gondi of Dantewada district); most of the units are in Hindi, ${ }^{3}$ as are concept-based subjects like math.

2) Provisions of two teachers, a Hindi and an ITM speaker, for Grades 1 and 2 (not mandatory).

3) The appointment of hostel/dormitory caretakers who speak the ITM languages.

The above listed initiatives, while progressive, may not necessarily translate to linguistic advantages or enhance the participative and communicative comfort within the classroom spaces for the ITM child (Rubio-Marin, 2007). A close examination of the structuring and functioning of ITM schools shows that several key theoretical principles can be found in these educational spaces. The principle of separation (but equal) formulated within discourses of affirmative action, legitimizes the establishment of special residential schools for ITM children.

\footnotetext{
${ }^{2}$ For a more detailed description, the reader is referred to this document on the NITI AYOGs website: https://niti.gov.in/writereaddata/files/bestpractices/Porta\%20Cabins\%20Residential\%20schools\%20for\%20child ren $\% 20 \mathrm{in} \% 20 \mathrm{LWE}$-affected $\% 20$ areas $\% 20 \mathrm{of} \% 20 \mathrm{Chhattisgarh.pdf.}$

${ }^{3}$ For e.g. Grade 4, the textbook has 16 units in Hindi, 2 in Gondi (Dantewada), 1 in Sanskrit and 1 in English.
} 
This implies that opportunities for home language (HL) development and the period for parentchild bonding are drastically reduced triggering serious consequences for cultural awareness, and home language development (Skutnabb-Kangas, 2020; Cummins, 2017). The development of context-reduced and cognitively-demanding language proficiency which is pivotal for academic literacy could be affected (Francis, 2000; Cummins, 2011; Chimirala, 2017). Principle of monolingualism as Clyne (2008) explains, recognizes, represents and places one language as the language of socio-economic mobility, e.g. Hindi. The principle of language parity which provides for the right to communicative comprehension for the ITM child (point 3 above) is not obligatorily implemented. Such educational context restricts HL-exposure and impedes/delays HL development (Cummins, 2017), restricts the availability of HL as a scaffold during cognitively-demanding and context-reduced tasks (Setati et al., 2002) and thus a creates a possibility for conditions that lead to a higher likelihood of the child exhibiting characteristics similar to DLD (Fenemma-Bloom, 2010) since neither the HL nor the school language (SL) may be age-appropriate.

\section{Some theoretical considerations that inform the adaptation (and the study)}

\subsection{Processing modes of the child}

\footnotetext{
"For us [in the developing world], many languages are facts of existence, three languages a compromise, two languages are a tolerable restriction, one language is absurd." (Pattanayak, 1986: 143)
}

The quote above by Pattanayak (1986) succinctly captures the linguistic way of life in India which theoretically can be analysed in terms of Grosjean's 'Complementarity Principle'. Grosjean (1997: 175) defines the principle as: "bilinguals acquire and use their languages for different purpose, in different domains of life, with different people. Different aspects of life normally require different languages" and so he uses this logic to underscore the fact that bilinguals develop a level of fluency that is directly proportional to the need for that language and the domain-specificity of the need. This understanding of a bilingual's language repertoire necessarily begs our engagement as researchers with literature pertaining to bilingualism since bilingual language repertoire involves varying degrees of interconnectedness, interrelationship and interdependence among the linguistic faculties, the general cognition and the mechanisms involving the interaction of the two (Francis, 2000: 196; Hall et al., 2006; Jessner, 2008).

According to Grosjean (1989: 6) "a bilingual is not a sum of two complete or incomplete monolinguals; rather, has a unique and a specific linguistic configuration that cannot be reduced to two monolingual systems" and who controls the language mode and hence activates those language systems that the communicative requirement demands. A mode as a "state of activation of the bilingual's languages and language processing mechanisms" (Grosjean, 1998: 25 ) conceives of bilingual ability as adaptive and dynamic in response to new challenges posed by processing demands of tasks, interlocutors and so on. Building further on these ideas, Cook (2003: 10-13) proposes an integration continuum where three possibilities of how languages 
could be psycho-linguistically related are hypothesized: complete separation of languages on one end, partial overlap of language systems in the middle and complete integration. Hall et al. (2006: 223) succinctly explains a bilingual's cognition as "a super-mental system containing components of each language system in addition to components that are not specific to either system", a constantly evolving, dynamic and fluid super-system that is 'activated' by the nature of the task and within the boundaries of which a possibility of 'transfer' across languages can be conceptualized. Hence the processing mode in which the child is as a task is being performed becomes a mediating variable and a methodological challenge (Diaz, 1985).

\subsection{Exposure enables performative ability and conceptual knowledge}

Exposure is often 'objectively' operationalized as a temporal variable that correlates with language competence, i.e. knowledge of lexical, syntactic aspects (Hammer, Lawrence \& Miccio, 2008). I argue that in working with bilingual children from ITM communities, performative ability would be a more realistic estimate of the child's language capability than a documentation of 'competence' (Daller \& Ongun, 2017). By performative ability, I refer to the extent to which exposure nurtures the child's ability to control intra-language domains (Squires et al., 2014; lexical and syntactical components of a language) to code one's communication. In the case of an ITM child, the child's relative performative ability is the outcome of exposure. Pertinent at this juncture is Cummins concept of threshold level of language ability that bilingual children should reach: the lower one, which is also chronologically the first one, should guard them from negative effect on their cognition, but the attainment of "a second, higher-level of bilingual competence might be necessary to lead to accelerated cognitive growth" (Cummins, 1979: 245), i.e. a positive effect and transfer for both the languages especially at the conceptual problem-solving level. Further, research finds that vocabulary knowledge is closely linked to exposure, bilingual cognition and intelligence (Hammer et al., 2008). However, studies that investigate vocabulary knowledge in bilinguals report a 'bilingual gap', i.e. a deficit in vocabulary knowledge is found in bilinguals when comparing their performance in one language with monolingual control groups (see Thordardottir, 2011). These comparisons that indicate a 'bilingual gap' do so without taking into account that a bilingual uses his/her languages for different domains and different purposes (Grosjean, 1998). For example, vocabulary pertaining to emotional words and conversational strategies for friendly conversations could be well developed in Gondi/Halbi, but not in Hindi. Similarly, cognitive verbs and discourse markers could be available in Hindi but not in Gondi/Halbi, since these are literacy-based discourse features (in line with the complementary principle; Grosjean, 1998). Consequently, bilinguals develop differential domain-specific vocabularies in the two languages. Pearson et al. (1993) propose the notion of total conceptual vocabulary (TCV), where vocabulary knowledge is counted regardless of the language in which it is expressed or understood. In short, as De Houwer, Bornstein and Putnick (2014) explain, instead of counting the words in each language, the child needs to be credited for knowing the concept. This understanding regarding bilingual vocabulary becomes important 
while adapting MAIN and in evaluating their narratives, especially with respect to Internal State Terms (IST).

\subsection{Bruner's landscape of indexical-actions and consciousness}

Bruner (1986) pointed out that stories are positioned at the interface of two distinct landscapes: the landscape of the indexical-visual-actions and the landscape of consciousness (i.e. characters' inner worlds). A child needs to traverse the two and make a quantum leap in connecting the visible-action-sequence with the complex consciousness within the contours of the thematic specificities of the events and time-frames of the story in which the characters act (i.e. Theory on Mind). Therefore, availability of the mental language is an absolute requirement if the child is expected to not just comprehend, but also talk about the characters motivations or even speculate on what the character is trying to do. Therefore, according to Bruner, narratives tap into the cognitive-linguistic resource pools. As Hudson and Saphiro (1991) point out a strong interdependence between cognitive and linguistic discourse levels and that further is linked to the acquisition of an articulated mental language, which allows for reference to feelings, emotions, and thoughts.

The added complexity in academic settings of the potacabin schools is that the nature of exposure to the two languages is not identical and hence while receptive vocabulary/language might exist, expressive vocabulary might lag behind since vocabulary is dependent on input (Pearson, 2002; 1993), vocabulary development is proportional to the amount of exposure (Hammer, Lawrence, \& Miccio, 2008) and the rate of development of receptive and expressive vocabulary varies with expressive vocabulary trailing behind receptive vocabulary and the development of both are bound to 'meaningful' input (Thordardottir, 2011). Therefore, the need for community engagement as well as the school's help in estimating the linguistic repertoire of the child was an absolute requirement for adapting MAIN, if MAIN was to document the child's communicative (performative) ability as sensitively as possible (Sarangi, 2017).

\section{Adapting MAIN for use with the Gondi- and Haldi-Hindi speaking populations}

Four specific concerns guided the adaptation and translation of MAIN to the two ITM languages, Gondi and Halbi. The first being the need to ensure that MAIN would leverage (Michales, 2005) the ITM child's cultural, cognitive and linguistic resources without triggering negative affective responses. The second concern was whether MAIN was culturallyappropriate and valid for the Gondi and Halbi children. The third concern, which arised in the wake of the fact that practically no research exists with children attending the potacabins schools regarding their linguistic repertoires. Finally, the fourth concern was that the modifications/adaptations should not alter the episodic logic of the stories in MAIN. In order to culturally validate the MAIN story content, we sought the help of the community members of both the communities throughout the adaptation process. We requested the village headman 
to help us in the adaptation process. We asked for the following community members to be a part of the team: a teacher, an anganwadi 'early childhood and nutrition center' employee and a parent who had experienced the potacabin system. Several rounds of Focus Group Discussions (FDG) were held with each community separately in order to develop a culturallysensitive and linguistically representative version of MAIN. The processes of adapting MAIN to Gondi and Halbi are presented in Table 1 and 2. The process of adapting MAIN to Hindi for use with these populations is described separately in Section 4.3. 
Table 1. Adaptation process: Gondi MAIN.

\begin{tabular}{|c|c|c|c|c|}
\hline Focus Group & FGD 1 & FGD 2 & FGD 3 & FGD 4 \\
\hline $\begin{array}{l}\text { Discussions } \\
\text { (FGD) }\end{array}$ & $\begin{array}{l}\text { Objective: } \\
\text { To understand storytelling as a } \\
\text { cultural practice. } \\
\text { To compare the components of } \\
\text { home story-telling with the } \\
\text { macrostructural framework used } \\
\text { in MAIN. }{ }^{4} \\
\text { Purpose: } \\
\text { To understand the structure, } \\
\text { themes, animation, } \\
\text { personification and intention } \\
\text { behind storytelling as a cultural } \\
\text { and home practice. } \\
\text { To estimate similarities and } \\
\text { differences between the } \\
\text { components of the story } \\
\text { structure. }\end{array}$ & $\begin{array}{l}\text { Objective: } \\
\text { To gauge the cultural appropriacy } \\
\text { of the four MAIN stories. } \\
\text { Purpose: } \\
\text { To ensure that neither } \\
\text { unknown/unfamiliar props nor } \\
\text { actions in the MAIN picture- } \\
\text { sequences restrict the child's } \\
\text { storytelling or trigger silence or } \\
\text { reticence or confusion in } \\
\text { storytelling }\end{array}$ & $\begin{array}{l}\text { Objective: } \\
\text { To reevaluate the cultural- } \\
\text { appropriacy of the four MAIN } \\
\text { stories after necessary changes } \\
\text { were made. } \\
\text { To engage the community in } \\
\text { estimating whether children in } \\
\text { potacabins would possess the } \\
\text { linguistic competence needed to } \\
\text { narrate the stories. } \\
\text { Purpose: } \\
\text { To ensure that the linguistic tokens } \\
\text { required for uttering the ideas are } \\
\text { part of the community languaging. } \\
\text { To discuss the script to use for } \\
\text { writing the Gondi MAIN. }\end{array}$ & $\begin{array}{l}\text { Objective: } \\
\text { To scrutinize the scoring sheets } \\
\text { and be aware of possible concerns } \\
\text { the community might raise. } \\
\text { Purpose: } \\
\text { To be aware of dialectical } \\
\text { variation in and the occurrence of } \\
\text { possible alternative constructions. }\end{array}$ \\
\hline $\begin{array}{l}\text { Concerns } \\
\text { indicated }\end{array}$ & $\begin{array}{l}\text { NONE (because this phase was } \\
\text { exploring the community } \\
\text { practice of story-telling). }\end{array}$ & $\begin{array}{l}\text { The human characters were } \\
\text { 'foreign.' Sausage was } \\
\text { unfamiliar; replacement with fish } \\
\text { in the traditional way of carrying } \\
\text { fish suggested. }\end{array}$ & $\begin{array}{l}\text { More child-sensitive alternative } \\
\text { constructions should be included. }\end{array}$ & $\begin{array}{l}\text { Not sure if the expectations of } \\
\text { macrostructural complexity would } \\
\text { be found in children' } \\
\text { performances. } \\
\text { Alternate formulations owing to } \\
\text { three aspects (discussed in } 4.1 \text { ) }\end{array}$ \\
\hline $\begin{array}{l}\text { Changes } \\
\text { made }\end{array}$ & NONE. & $\begin{array}{l}\text { Adapting the human characters by } \\
\text { darkening the complexion and } \\
\text { hair. } \\
\text { Replacing sausage with fish. }\end{array}$ & $\begin{array}{l}\text { NO changes made until after FGD } \\
4 \text { and piloting. }\end{array}$ & $\begin{array}{l}\text { Adopted the Devnagari script for } \\
\text { writing the Gondi MAIN. } \\
\text { Alternatives included after } \\
\text { piloting and main study. }\end{array}$ \\
\hline
\end{tabular}

${ }^{4}$ The communities were requested to record any story telling occasion. We received 8 such recordings from the Gond community, 5 in Gondi and 3 in Halbi. Stories were narrated by grandparents and grandaunts. Intercommunity marriages are common and so multilingualism between Gondi and Halbi and Chattisgarhi is a normal languaging reality. All the macrostructural components were reflected in the stories. Additionally, stories mostly ended in a moral.

${ }^{5}$ Gondi has its own script, the Gunjala Gondi script, which is not used in general. Thus, which script that should be used for writing the Gondi MAIN had to be discussed. 
Table 2. Adaptation process: Halbi MAIN.

\begin{tabular}{|c|c|c|c|}
\hline \multirow{2}{*}{$\begin{array}{l}\text { Focus Group } \\
\text { Discussions (FGD) }\end{array}$} & FGD 1 & FGD 2 & FGD 3 \\
\hline & $\begin{array}{l}\text { Objective: } \\
\text { To understand story and storytelling as a } \\
\text { cultural practice and whether the } \\
\text { macrostructure aspects are reflected in } \\
\text { community story-telling. } \\
\text { Purpose: } \\
\text { To ensure that neither unknown/unfamiliar } \\
\text { props nor actions in the MAIN picture- } \\
\text { series restrict the child's storytelling nor } \\
\text { trigger silence or reticence or confusion in } \\
\text { storytelling. }\end{array}$ & $\begin{array}{l}\text { Objective: } \\
\text { To evaluate if the MAIN modifications as } \\
\text { recommended by the Gond community was } \\
\text { culturally-appropriate for the Halbi child. } \\
\text { To engage the community in estimating } \\
\text { whether children in potacabins would possess } \\
\text { the linguistic competence to narrate the stories. } \\
\text { Purpose: } \\
\text { To ensure that linguistic token required to utter } \\
\text { the idea is a part of the community languaging. } \\
\text { To discuss the script in which to write the } \\
\text { Halbi MAIN. }\end{array}$ & $\begin{array}{l}\text { Objective: } \\
\text { To scrutinize the scoring sheets and be } \\
\text { aware of possible concerns the } \\
\text { community might raise. } \\
\text { Purpose: } \\
\text { To be aware of dialectical variations } \\
\text { and occurrence of possible alternative } \\
\text { constructions }\end{array}$ \\
\hline Concerns indicated & $\begin{array}{l}\text { NONE (because this phase explored the } \\
\text { community practice of story-telling). }\end{array}$ & $\begin{array}{l}\text { Alternative constructions to be included so that } \\
\text { children's utterances are not invalidated (and } \\
\text { thus negatively scored). }\end{array}$ & $\begin{array}{l}\text { Highlighted a 'visual-bias' in } \\
\text { responses the scoring sheets. } \\
\text { Apprehensions about whether } \\
\text { macrostructural complexity (as } \\
\text { designed in MAIN) would be } \\
\text { evidenced in children' narratives. } \\
\text { Alternate formulations owing to } \\
\text { auditory stimulus (discussed in detail } \\
\text { in 4.1) }\end{array}$ \\
\hline Modifications made & NONE. & NO changes made until after pilot study. & $\begin{array}{l}\text { Adopted the Devnagari script for } \\
\text { writing the Halbi MAIN. } \\
\text { Alternatives included after piloting and } \\
\text { main study. }\end{array}$ \\
\hline
\end{tabular}

${ }^{6}$ Like with the Gond community, the Halaba Community was asked to record any story-telling events in their homes. No recordings were handed in, but the community members mentioned that stories in Halbi were a part of children's everyday lives until they start attending the Potacabin schools. 


\subsection{Adaptations included}

This section describes the changes that were made to the Halbi and Gondi MAIN-versions (compared to the original MAIN) as a result of the adaptation process (see Tables 1 and 2).

\subsubsection{Changing sausages to fish}

Figure 2 shows the difference between the original MAIN Dog story pictures and the adapted ones: the sausages were replaced with fish that were held in the way the community usually carries it. As shown in Figure 2, the human character was modified so that both hair and complexion were darkened (the same was done for the human character in the Cat story as well). These adaptations were carried out in agreement with the MAIN authors.
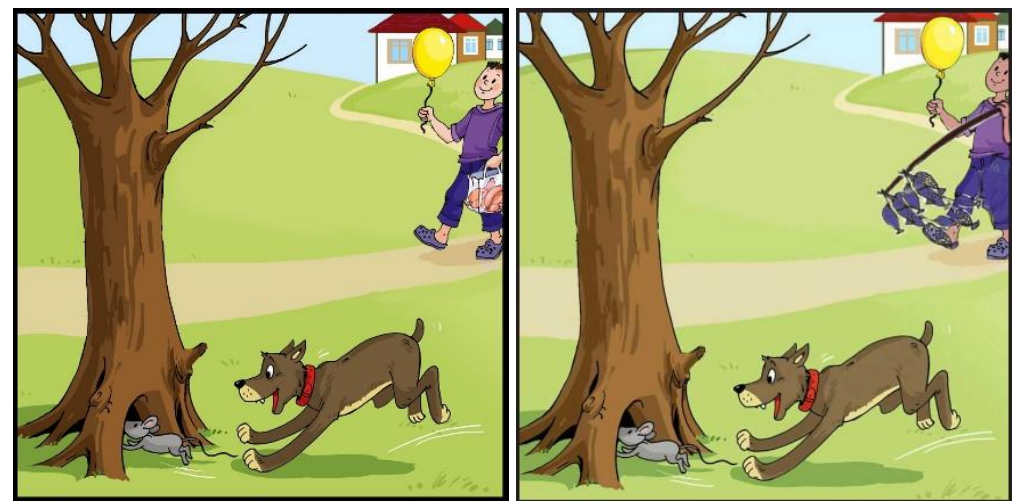

Figure 2. Picture 2, Dog: original MAIN stimuli (left) and adapted version for use with Gondi- and Halbi-speaking children (right). Copyright 2020 by ZAS Papers in Linguistics.

\subsubsection{Concerns with alternative lexical items}

The community members (and the native-speaker field assistants) highlighted possible alternative names for common lexical items based on three factors: the geographical location of the community, access to Hindi and the availability of intergenerational communication (in Gondi and Halbi) for the child. For example, a common word like 'cat' had three different geolocational (dialect) representatives in Gondi: bhilai (/bhilai/), poosaal (/pu:sa:1/) and verkoode (/verkod/). What word would the child use for 'cat' (in the Cat Story)? That would depend on who the child has grown up with (+/- Inter-generational communication), where the child grew up (geo-locational factor and the amount of Hindi exposure the child has had (+/- exposure to Hindi). If the child grew up with the grandparents, the chances of the child using verkood were extremely high. This was the term used by the older/elder generations. If the child grew up in the rural areas around Dantewada, chances of using poosaal were high. If the child was an urban dweller and exposed to Hindi, then given the rare cognate possibility between Hindi (/bili:/ 'cat') and Gondi, bhilai was likely to be used. Based on a combination of the three factors, one or more of the words could be used. Therefore, all three were included in the scoring sheet for the Cat story (although not in the story scripts).

In the case of Halbi, the ubiquitous language shift that the community has been experiencing was an added factor. For example, a common word like 'good' as in 'feel good' 
or even 'good child' had three different alternatives in Halbi: nangath (/nang $\mathrm{at}^{\mathrm{h}} /$ ), niko (/nik ${ }^{\mathrm{h}} /$ ) and the Hindi loan word achaa (/atfa/). If the child grew up with the grandparent generation living in Bastar (not Dantewada), then the chances of the child using niko were extremely high since this was the term the older ITM generation used. If the child grew up in the rural areas around Dantewada, nangath was frequently used in the input. If the child was an urban dweller and exposed to Hindi, achaa was likely to be frequently used.

\subsubsection{Inclusion of auditory perceptions in the scoring sheets}

The Halbi community members expressed the opinion that the correct responses in the scoring sheets were 'visually' biased and neglected 'auditory' responses. They explained that living in forest and wilderness necessitates survival traits which require more attention to sounds than to vision. They explained that the rustle of the leaves, the breaking of a twig, the falling of a fruit, the screech of a monkey, and similar signs take on an indexical relationship with a lurking danger or hunt. For question D3 in the Baby Birds story which asks why the child thinks that the baby birds are hungry, the community members pointed out that the child could respond by saying caw caw gaggese 'crying/doing caw caw', i.e. the baby birds are cawing, instead of saying that 'the baby bird's mouth/beak is open'. The community members pointed out that a possibility that the child will interpret the 'open mouth' not as a visual input but as an auditory stimulus should not be ruled out. This option was included in the options of correct responses in scoring sheets (and we did get this response from 3 of the children in our pilot study; we included this in the Gondi version too).

\subsection{Validation of the scoring sheets and protocols in Gondi and Halbi}

Our search for a trained linguist who had studied Gondi (as suggested in the guidelines by Gagarina et al., 2019) did not yield any result despite the fact that Gondi has been 'documented' and 'dictionarised' as a part of its project on Endangered Languages by Central Institute of Indian Languages (CIIL). For this reason, we worked together with a Gondi textbook writer from the State Education Board. The first round of evaluation was internal with the author, the translators and the Gondi textbook writer. In this round, the purpose was to check whether the translations were appropriate, whether alternative ways of representing the same semantic idea existed and to suggest such alternatives. The textbook writer suggested that we again crosscheck with the ITM community on the contents of the protocols and scoring sheets, to revise the scoring sheets based on actual child's response to the narratives after the pilot study and again after the main study. All three suggestions were implemented.

The Halbi scoring sheets and protocols were validated by a $\mathrm{PhD}$ student in a public university. He checked for content appropriacy across the stories and for possible syntactic and lexical errors as well. Additionally, three Halbi community participants were invited to check the linguistic appropriacy of the protocols, investigate the possibility of inclusion of alternative lexical items, evaluate the scoring sheets from the perspective of a child's repertoire (the community participants were also parents). The one change they suggested was to include loan words from Hindi and to be sensitive to the context in which the child is growing up. 


\subsection{Adaptation of MAIN to Hindi}

The work on adapting MAIN to Hindi for use with the two ITM-speaking school children populations was taken up twice. The first time, in May 2018, at the university, we (the author and 8 English-Hindi-L1 ${ }^{1}$ multilingual Masters student-interns) translated the English MAIN (Gagarina et al., 2012). Far from the reality of Dantewada potacabin school system and equipped with the realization that our work with the ITM community and field research assistants cannot be carried out with the English MAIN, the first Hindi adaptation was a translated version of the English version (in fact, it can be called a 'Hindi replica' of the English version). The need for the first translated version of MAIN Hindi was to start engaging our field research assistants (RAs) and the members of the two ITM communities (Gondi and Halbi).

The second time when we began to adapt MAIN to Hindi was after the community interactions (FGDs) and the validation (by experts and community) and the piloting of Gondi and the Halbi versions (with children) had been carried out. The purpose of the second round of translation of MAIN was to Hindi incorporated the modifications from the Halbi and Gondi versions and the revised MAIN (Gagarina et al., 2019). Additionally, this time round, we were conscious of the variations that exist in Hindi and Chhattisgarhi. Census India estimates Hindi to be spoken by about $41 \%$ of the Indian population as a mother tongue. A total of 43 dialects (languages) are classified as dialects of Hindi under the broad category of 'Hindi-speaking-belt' or Hindi continua. Chhattisgarhi, which is the official language of the State of Chhattisgarh, is included as a dialect of Hindi; therefore, the decision as to whether the 'Chhattisgarhi' variations had to be included in the scoring sheets had to be taken. We constructed a word list (with nouns, verbs, adjectives and IST) in Hindi and Chhattisgarhi and noticed differences like the following: goat in Hindi is 'bakari' / $\mathrm{b}^{\mathrm{h}}$ akari/ (female: singular), but in Chhattisgarhi the word would be $/ \mathrm{b}^{\mathrm{h}} \mathrm{ok}^{\mathrm{h}}$ ari:/ (male: singular) and 'cheri' /fferi:/ (female: singular). We decided to consult teachers in schools and also the pilot data for any inclusions in the scoring sheets. We requested help from three primary school teachers who teach from Grade 1 to Grade 5 in different schools. The process of adapting MAIN to Hindi is presented in Table 3.

Table 3. Adaptation process: Hindi MAIN for use with Gondi- and Halbi-Hindi bilinguals.

\begin{tabular}{|c|c|c|c|c|}
\hline & & $\begin{array}{l}\text { Teacher } 1 \\
\text { response }\end{array}$ & $\begin{array}{l}\text { Teacher } 2 \\
\text { response }\end{array}$ & Teacher 3 response \\
\hline $\begin{array}{l}\text { Teacher validation of the } \\
\text { MAIN version based on } \\
\text { changes and inclusions } \\
\text { suggested by the ITM } \\
\text { communities }\end{array}$ & $\begin{array}{l}\text { Objective: } \\
\text { To estimate whether } \\
\text { children in the } \\
\text { potacabin schools } \\
\text { would possess the } \\
\text { linguistic competence } \\
\text { to narrate the stories in } \\
\text { Hindi. } \\
\text { Purpose: to ensure the } \\
\text { linguistic tokens }\end{array}$ & $\begin{array}{l}\text { No comments } \\
\text { made. } \\
\text { Found the text } \\
\text { simple. }\end{array}$ & $\begin{array}{l}\text { No comments } \\
\text { made. } \\
\text { Found the text } \\
\text { simple. }\end{array}$ & $\begin{array}{l}\text { Expressed concern } \\
\text { regarding internal } \\
\text { state terms (IST), } \\
\text { especially the } \\
\text { emotional and } \\
\text { cognitive categories. } \\
\text { She highlighted that } \\
\text { the child may be } \\
\text { aware of the } \\
\text { intentions and }\end{array}$ \\
\hline
\end{tabular}

\footnotetext{
${ }^{1}$ The interns' L1s were Telugu, Malayalam, Hindi, Bangla and Urdu.
} 


\begin{tabular}{|l|l|l|l|}
\hline & $\begin{array}{l}\text { required to utter the } \\
\text { ideas are part of the } \\
\text { child's language } \\
\text { environment. }\end{array}$ & & $\begin{array}{l}\text { mental states, but } \\
\text { that words in Hindi } \\
\text { may not be available, } \\
\text { especially for } \\
\text { cognitive verbs like } \\
\text { 'observe, stare, plan, } \\
\text { notice', etc. }\end{array}$ \\
\hline Cross-checking & $\begin{array}{l}\text { Two RAs listed all the content words (nouns, verbs, adjectives and adverbs) from } \\
\text { language books used in Grades 1-3. }\end{array}$ \\
& $\begin{array}{l}\text { Two RAs engaged in classroom observations of children in Grade 2 on how the story } \\
\text { 'the lion and the rat' was taught. The teachers' interactions with the children contained } \\
\text { words like think, plan, and notice and so on. }\end{array}$ \\
& $\begin{array}{l}\text { Retain the category of words as such on the scoring sheets and proceed with the piloting. } \\
\text { Following the pilot study, no Chhattisgarhi words were included in the scoring sheets. }\end{array}$ \\
\hline
\end{tabular}

\subsection{Adapting the background questionnaire to Gondi and Halbi}

In order to be able to use the MAIN background questionnaire to gather information about the backgrounds of the children from these populations, a number of changes were made to the questionnaire. Question 4 asking about to the child's country of birth was changed to 'State', to collect information about which of the 29 Indian states the child was born in. Question 22 was found problematic as it to presume that the child lives in an urban setting, has access to technology (e.g. TV) and lives with literate parents. So, instead of modifying the question, we included the option of 'family and community participation' in the form of two different items: 1) participating in cultural activities at home and school and 2) whether the child was taking care of a younger sibling/cousin/another child at school or at home. Both these items were meant to help gain an estimate of the extent of home language (L1) use, at least for basic interpersonal communication purposes. We also added the option of 'radio' to item 3 of question 22 in addition to TV and computer games. We were aware that language activist groups in this district air radio programmes in Gondi and Halbi and it was possible that the child had access to a radio. Therefore, it is possible that the child had access to a radio. We also added an addition question (Question 23) to supplement the exposure component as 'language use' in Gondi/Halbi, as shown in Table 4. This question could be administered verbally by native-speaking RAs in consultation with the child.

Table 4. Question 23 in the Gondi and Halbi background questionnaires.

\begin{tabular}{|l|l|l|}
\hline S. No & \multicolumn{1}{|c|}{ Descriptors } & Exposure \\
\hline 1 & less than 15 minutes of conversation with peers in Gondi/Halbi. & $0 \%$ \\
\hline 2 & 30 minutes of: conversation, play with peers and hostel caretakers in Gondi/Halbi. & $5 \%$ \\
\hline 3 & $\begin{array}{l}\text { 60 minutes of conversation, play with peers, discussion with peers and juniors along with } \\
\text { hostel caretakers in Gondi/Halbi. }\end{array}$ & $10 \%$ \\
\hline 4 & $\begin{array}{l}90 \text { minutes of conversation, discussion with peers and juniors along with hostel caretakers } \\
\text { + explaining math or some difficult concept to a peer in Gondi/Halbi in hostel spaces. }\end{array}$ & $20 \%$ \\
\hline 5 & $\begin{array}{l}\text { 90 minutes of conversation, discussion with peers and juniors along with hostel caretakers } \\
\text { +explaining math or some difficult concept to a peer in Gondi/Halbi in hostel spaces and } \\
\text { CLASSROOM space. }\end{array}$ & $25 \%$ \\
\hline
\end{tabular}




\subsection{Method}

\subsubsection{Participants and Recruitment}

Access to children in Grades 1 and 2 was denied citing security, shyness/reticence and age as reasons in all the five potacabin schools in Dantewada that we approached for the study. However, the school authorities allowed us access to children in Grades 3, 5 and 7 for the study. In this paper, we report on data collected from two schools. All children in grades 3, 5 and 7 were invited to an introduction which was in Halbi/Gondi. We adopted a two-part recruitment procedure. The first part of the criteria was physiological: no hearing loss or speech issues, living in the potacabin school since Grade 1, and the ability to speak both Halbi/Gondi and Hindi. The second part of the criteria was based on results from a three-component screening test to identify language dominance and whether a threshold bilingual ability was available, i.e. whether performative ability on cognitively demanding tasks in SL and HL was sufficiently developed to process and perform in that language. The tests assessed picture comprehension (component 1), vocabulary (receptive, productive and analogy, component 2) and mathematical word problems (component 3). ${ }^{2}$ The mathematics component was added to identify the language dominance and whether a threshold bilingual ability was available.

Instructions for administrating MAIN guided the administration of the three-component test. Hindi-speaking RAs conducted the tests individually with each child on a computer. For all three components, the failed items were re-administered by a Halbi-Speaking RA and any correct responses were added to the score (Pearson et al., 1993; Muñoz-Sandoval, Cummins, Alvarado, \& Ruef, 1998; see also Section 4.3). Time was set at 60 minutes for Grade 5 and Grade 7 but no time-limit was set for Grade 3 (to avoid test anxiety). Availability of a threshold bilingual ability and processing modes was based on component 3. Children, who scored lesser than one standard deviation lower than the mean score on any of the three components were not included in the study. The three age groups differed in their 'performative' language dominance, as shown in Table 5. Table 5 also gives an overview of the children's scores on the three components, by grade.

Table 5. Mean (SD) on the recruitment test for Language Dominance and TBA.

\begin{tabular}{lllllll}
\hline Grades & $\mathrm{N}$ & $\begin{array}{l}\text { Component 1: picture } \\
\text { comprehension } \\
\text { Mean (SD) }\end{array}$ & $\begin{array}{l}\text { Component 2: } \\
\text { Vocabulary } \\
\text { Mean (SD) }\end{array}$ & $\begin{array}{l}\text { Component 3: } \\
\text { Mathematics } \\
\text { Mean (SD) }\end{array}$ & $\begin{array}{l}\text { Language } \\
\text { Dominance }\end{array}$ & TBA \\
\hline Grade 3 & 18 & $7.2(1.6)$ & $18.1(3.2)$ & $5.1(1.3)$ & Halbi & No \\
Grade 5 & 18 & $7.8(1.3)$ & $20.2(3.2)$ & $5.6(1.2)$ & Halbi-Hindi & Evolving \\
Grade 7 & 18 & $7.6(.8)$ & $24.4(2.6)$ & $5.5(1.5)$ & Hindi & Yes \\
\hline
\end{tabular}

Note. $\mathrm{TBA}=$ threshold bilingual ability.

\footnotetext{
${ }^{2}$ The mathematical word problems were adopted from the National Achievement Survey, India, 2017 and 2018.
} 
Grade 3: 18 children in Grade 3 were included. All of them responded to the math and pictorial analogies in Halbi indicating performative dominance in Halbi on cognitively demanding tasks and showing an absence of available threshold bilingual ability, i.e. the performative ability on cognitively demanding tasks in L2 Hindi is not sufficiently developed to process and perform in that language.

Grade 5: 18 children in Grade 5 were included. 13 out of 18 children successfully completed a portion of the math in Halbi, which indicates that in Grade 5, performative dominance is available in L2 Hindi for visually and contextually-supported components while for the operationally demanding components such as in math performative dominance is in L1 Halbi. Therefore, an evolving threshold bilingual ability is noticed.

Grade 7: 18 children were included from Grade 7. Only 2 (out of 18 and on 3 problems) attempted the math task in L1 Halbi, thus indicating a performative dominance on cognitively demanding tasks for a majority in L2 Hindi and a possibly readily available threshold bilingual ability in place.

\subsubsection{Procedure}

All 54 children narrated one story each in both the telling and the retelling mode in L1 Halbi and L2 Hindi, i.e. a total of 4 stories were elicited from each child. The order of eliciting narratives was counter-balanced for languages and stories. Native speaking RAs elicited the narratives with an interval of 25 days between the two languages. All narratives were audio recorded and transcribed by RAs who were meticulously trained to transcribe. Each audio file underwent two stages of cross-checking before being transcribed: whether the entire session was recorded and whether any white noise distorted the quality of the recording. In the latter case, the audio file was transcribed with the help of a native-speaker teacher (who also helped in adapting and translating MAIN to Halbi). Once transcribed, each of the transcripts was crosschecked word-to-word with the audio file by a different RA before the transcript was scored. The transcribed narratives were first marked for the story elements i.e. setting, time and three episodes, after which the goal, action, outcome and internal states terms for each episode were identified and scored. Every scored transcript was then checked by another RA and disagreements were resolved through discussion. The Cohen's $k$ between the raters for Halbi and Hindi were .94 and .91, respectively. Additionally, $15 \%$ of the Hindi transcripts were rescored by the author.

\subsubsection{Measures investigated}

The narratives were coded for two measures of narrative macrostructure: Story Structure (SS) and Structural Complexity (SC).

Story Structure: The narratives were scored for story structure following the MAIN scoring protocol, where the 3 episodes are scored for 5 components each (15 points) along with the setting and time scores ( 2 points) which gives a maximum of 17 points for the story structure score.

Structural Complexity: We coded each episode of the narratives for structural complexity as follows: AO (1 point), G or GA/GO (2 points) and complete episodes of GAO 
( 3 points). Hence, the maximum score is 9 points, which is given if the child produces a GAOsequence in all three episodes.

\subsection{Results}

Table 6 shows the means and standard deviations for the story structure score (SS) and story complexity (SC) by grade, elicitation mode (retelling, telling) and language 8Habli, Hindi). A repeated-measures ANOVA was first performed for each grade separately, followed by an ANOVA which compared the bilinguals' narratives between three Grades (Grade 3, Grade 5 and Grade 7), while taking language and elicitation mode into account.

Table 6. Mean (Standard Deviation) for story structure (SS) and story complexity (SC) in the L1 Halbi and L2 Hindi narratives of Halbi-Hindi bilingual children, by grade and elicitation mode (retelling, telling).

\begin{tabular}{|c|c|c|c|c|c|c|c|c|c|c|c|c|}
\hline & \multicolumn{4}{|c|}{$\begin{array}{l}\text { Grade } 3 \text { ( } 2 \text { years Hindi } \\
\text { exposure; Halbi dominant), } \\
\mathrm{N}=18\end{array}$} & \multicolumn{4}{|c|}{$\begin{array}{l}\text { Grade } 5 \text { ( } 4 \text { years Hindi } \\
\text { exposure; evolving threshold } \\
\text { bilingual ability), } N=18\end{array}$} & \multicolumn{4}{|c|}{$\begin{array}{l}\text { Grade } 7 \text { (6 years Hindi } \\
\text { exposure; Hindi dominant), } \\
\mathrm{N}=18\end{array}$} \\
\hline & \multicolumn{2}{|c|}{ Retelling } & \multicolumn{2}{|c|}{ Telling } & \multicolumn{2}{|c|}{ Retelling } & \multicolumn{2}{|c|}{ Telling } & \multicolumn{2}{|c|}{ Retelling } & \multicolumn{2}{|c|}{ Telling } \\
\hline & Halbi & Hindi & Halbi & $\mathrm{di}$ & Halbi & Hindi & Halbi & & Halbi & $\mathrm{Hi}$ & Halbi & 11 \\
\hline SS & $\begin{array}{l}9.00 \\
(2.16)\end{array}$ & $\begin{array}{l}7.60 \\
(2.67)\end{array}$ & $\begin{array}{l}10.23 \\
(1.78)\end{array}$ & $\begin{array}{l}33 \\
51)\end{array}$ & $\begin{array}{l}8.60 \\
(2.17)\end{array}$ & $\begin{array}{l}7.68 \\
(1.97)\end{array}$ & $\begin{array}{l}10.50 \\
(1.7)\end{array}$ & $\begin{array}{l}9.4 \\
(1 .\end{array}$ & $\begin{array}{l}8.13 \\
(1.20)\end{array}$ & $\begin{array}{l}8.72 \\
(1.72)\end{array}$ & $\begin{array}{l}9.08 \\
(2.10)\end{array}$ & $\begin{array}{l}9.94 \\
(2.60)\end{array}$ \\
\hline $\mathrm{SC}$ & $\begin{array}{l}4.52 \\
(.92)\end{array}$ & $\begin{array}{l}3.75 \\
(.75)\end{array}$ & $\begin{array}{l}5.72 \\
(.93)\end{array}$ & $\begin{array}{l}4.56 \\
(1.05)\end{array}$ & $\begin{array}{l}4.39 \\
(.97)\end{array}$ & $\begin{array}{l}3.72 \\
(1.05)\end{array}$ & $\begin{array}{l}5.75 \\
(.57)\end{array}$ & $\begin{array}{l}4.14 \\
(1.13)\end{array}$ & $\begin{array}{l}4.44 \\
(.85)\end{array}$ & $\begin{array}{l}3.97 \\
(.82)\end{array}$ & $\begin{array}{l}5.31 \\
(.58)\end{array}$ & $\begin{array}{l}6.40 \\
(1.40)\end{array}$ \\
\hline
\end{tabular}

For SS in Grade 3, a significant main effect of mode $(\mathrm{F}(1,68)=10.34, \mathrm{p}<.001)$ and a significant language effect of $(\mathrm{F}(1,68)=26.23) \mathrm{p}<.001)$ was found. A significant language $\mathrm{x}$ mode interaction was found $(\mathrm{F}(2,136)=9.03, \mathrm{p}=.03)$. Post-hoc test showed that L1 retelling was significantly higher than L2 retelling $(\mathrm{F}(1,34)=11.78, \mathrm{p}=.0023)$, L1 telling was significantly higher than $\mathrm{L} 1$ retelling $(\mathrm{F}(1,34)=9.42, \mathrm{p}<.001), \mathrm{L} 1$ telling was significantly higher than L2 telling $(\mathrm{F}(1,34)=5.86, \mathrm{p}=.03)$ and L2 telling was significantly higher than L2 retelling $(\mathrm{F}(1,34)=8.23, \mathrm{p}<.001)$.

For $S C$ in Grade 3, a significant effect for language was found $(\mathrm{F}(1,68)=13.89, \mathrm{p}<$. $001)$ and a significant effect of mode was found $(F(1,68)=11.31, p=.021)$. A significant language $\mathrm{x}$ mode interaction was found $(\mathrm{F}(2,136)=4.60, \mathrm{p}<.01)$. Post-hoc comparisons showed that L1 telling was significantly higher than $\mathrm{L} 2$ telling $(\mathrm{F}(1,34)=3.94, \mathrm{p}<.001)$; L1 retelling was significantly higher than $\mathrm{L} 2$ retelling $(\mathrm{F}(1,34)=15.22, \mathrm{p}=.02)$. L1 telling was significantly higher than $\mathrm{L} 1$ retelling $(\mathrm{F}(1,34)=5.106, \mathrm{p}=.0242)$.

For SS in Grade 5, a significant mode effect was observed $(\mathrm{F}(1,68)=10.64, \mathrm{p}<.002)$ and a significant language effect was also found $(\mathrm{F}(1,68)=26.23, \mathrm{p}<.000)$. A significant language $\mathrm{x}$ mode interaction effect was found $(\mathrm{F}(2,136)=12.69), \mathrm{p}<.031)$. Post-hoc comparisons showed that L1 telling was significantly higher L2 telling $(\mathrm{F}(1,34)=4.68, \mathrm{p}<$ $.001)$. Additionally, L1 telling was significantly higher than $\mathrm{L} 1$ retelling $(\mathrm{F}(1,34)=13.38, \mathrm{p}<$ $.000)$ and L2 telling was significantly higher than $\mathrm{L} 2$ retelling $(\mathrm{F}(1,34)=4.68, \mathrm{p}<.001)$. 
For SC in Grade 5, the effect of mode was not significant $(\mathrm{F}(1,68)=2.06, \mathrm{p}=.156)$, but a significant language effect was found $(\mathrm{F}(1,68)=13.89, \mathrm{p}<.02)$, with higher scores in L1 Halbi. The language $x$ mode interaction effect was not significant.

For $S S$ in Grade 7, there was a significant mode effect of $(\mathrm{F}(1,68)=10.64, \mathrm{p}=.002)$, with higher scores in telling, and a significant language effect $(F(1,68)=26.28, p<.000)$, with higher scores in L2 Hindi. The language $x$ mode interaction was not significant.

For $S C$ in Grade 7, the mode effect was not significant $(\mathrm{F}(1,68)=2.06, \mathrm{p}=.154)$, but the effect of language was significant language $(F(1,68)=13.89, p=.014)$, with higher scores in L2 Hindi. A significant language x mode effect was not observed.

Finally, the ANOVAs with Grade as between-subjects factor and Language and Mode as within-subjects factors showed a significant overall language effect both for $\mathrm{SS}(\mathrm{F}(1,204)=$ $6.87, \mathrm{p}=.009)$ and for $\mathrm{SC}(\mathrm{F}(1,204)=4.781, \mathrm{p}=.03)$, with significantly higher scores in L1 Halbi. The effect of mode was significant for $\operatorname{SS}(F(1,204)=8.08, p=.005)$, with higher scores in telling, but not for SC. There was a significant effect of Grade both for SS $(\mathrm{F}(2,204)=$ $32.315, \mathrm{p}<.001)$ and for $\mathrm{SC}(\mathrm{F}(2,204)=14.458, \mathrm{p}<.000)$. Post-hoc analyses for Grade showed that there was a significant difference between all three grades for both SS and SC. For SS, a significant difference was found between grade 3 and grade $5(-1.35, \mathrm{p}<.001)$, between Grade 3 and Grade 7(-2.49, p = .002) and between Grade 5 and Grade $7(-1.15, \mathrm{p}<.01)$. On SC, Grade 5 performed significantly higher than Grade $3(0.51, \mathrm{p}=.031)$, Grade 7 performed significantly better than Grade $3(0.90, \mathrm{p}<.006)$, and Grade 7 performed significantly better than Grade 5 ($0.31, p=.036)$. No significant interaction effect of grade $x$ language $x$ mode was found.

\subsection{Discussion}

Previous studies using MAIN have reported that performance on narrative macrostructural aspects (i.e. story structure and story complexity) consistently increased with age (Bohnacker (2016), that performance on retelling was invariant across languages and across ages (Kunnari et al. 2016), and that performance on retelling was significantly better than telling (Otwinowska et al., 2018; Kunnari et al., 2016). Our study supports the first finding that narrative performance increases with age. Additionally, our study finds different patterns of narrative performance on SS and SC between the grades. In Grade 3 and Grade 5, the children generally performed higher in L1 Halbi; however, in Grade 7, scores were significantly higher in L2 Hindi for both telling and retelling. This is likely because by this age, performative ability in L2 Hindi may be more enabled than in L1 Halbi (given the educational and residential context of the potacabin schools). Across the three grades and regardless of language significantly higher performance was found for telling compared to retelling. What can explain our findings?

One plausible explanation is that language dominance, i.e. performative ability on a task in a particular language and availability of a threshold level bilingual ability, could be significant mediating variables in bilingual narratives. Narrative performances, as Bruner (1986) explains, require a synergistic blend of two distinct landscapes, the landscape of the visual-indexical-actions and the landscape of the consciousness, implying that availability of the required language is a necessary condition for performance. It is possible that, in Grades 3 
and 5, the necessary language skills are available in L1 but not in L2, which explains why a higher level of episodic complexity was found for both retelling and telling in L1 compared to L2 in these groups (e.g. Severing \& Verhoeven, 2001 on Papiamento and Dutch languages). This pattern is different for the children in Grade 7, where performance in L2 is higher.

A second explanation, which is in tandem with the first one, is that a bilinguals' language performance on a task is contingent upon an interaction between (and among) learner-specific variables (such as bilingual proficiency, task familiarity and so on), and task-specific and elicitation-specific variables (such as task-inherent complexities, interlocutor and conditions of task elicitation). The results of this study can be interpreted as support for the claim that narrative macrostructure, and especially story complexity, which is closely linked to the cognitive maturation of an individual, is not completely independent of language capability. This seems to be the case to an even higher degree when the task is more cognitively complex as in telling which involves construction of causal and intentional elements as opposed to retelling which involves a reconstruction of the model story and so demands memory resources. In conclusion, the patterns reported here and necessitates the need to examine the interaction between task-internal characteristics, task modes, language demands and the child's performative ability (Gutierrez-Clellen, 2002; Simon-Cereijido \& Gutierrez-Clellen, 2009).

\section{$7 \quad$ Conclusion}

This paper has described the process of translating and adapting MAIN from English, a language that enjoys the highest vehicular power globally, to Hindi, a language that is constitutionally designated as the official language of India, and Halbi and Gondi (Dantewada), two languages that have relatively low ethnolinguistic vitality. In working with such minority/indigenous languages, this paper suggests that the following aspects be attended to while adapting and translating MAIN: know your 'sample/children' beyond the 'knowabledemographic-clinical' aspects by knowing the community to which the child belongs, factor in the nature of parenting and languaging the child is socialized into and constantly engages in, engage the community and other primary stakeholders involved, be conscious (and cautious) to whether the translations and adaptations have alternative linguistic constructions, and finally, be aware of how the assessment procedure could impact the child (and the community as well). For me as the researcher, the processes of interacting with ITM Community members, the teachers in the schools, the field researchers and the children has been a journey of revelation of my implicit social biases and of how the intricate and inextricable relationship between the social factors impacts (one can even say manipulates) the child's linguistic environment and the development of the child's language repertoire as a whole (Spolsky, 2019; and not just in task performance).

We have also reported the results from the first study of study Halbi-Hindi children who attend potacabin schools. While our data corroborates the general finding that macrostructure (story structure and structural complexity of the episodic events) increase with age, our data does not support two other findings: that macrostructure is 'invariant' across languages within 
an age group and that narrative performance is better on retelling. This study highlights the need for a finetuned analysis of the interaction between task-specific characteristics of the story prompt, the modality of narration (retelling/telling) and bilingual language profiles. The study highlights the need for more carefully-designed studies with the Halbi-Hindi speaking population in potacabin schools specifically and indigenous/minority contexts in general.

\section{Acknowledgments}

This study was funded by the Indian Council for Social Science Research (ICSSR), New Delhi, India through grant no: 02/139/2017-18/RP/MAJOR. The data reported on here is part of Project MELT. The support of the schools, teachers and the hostel caretakers in helping with the study is acknowledged. I thank the interns, Pragyan Chakroborty, Grace Isaac, Auromita Mitra, Priya Prithiviraj, Leanne Jacob, and Basitha Bishwas, who helped me with the first version of the Hindi MAIN. The infectious enthusiasm of the children who participated in many ways as they narrated the stories cannot be captured in words here. I am indebted to them. A special appreciation also to the field research assistants without whose help neither the adaptation nor my learning on the study would have been possible. A heart-felt gratitude to all the parent-community members whose concerns and conversation triggered several unlearning experiences. I am deeply indebted to Prof. Natalia Gagarina and Dr Josefin Lindgren for their valuable feedback on drafts of this paper.

\section{$9 \quad$ References}

Aldrich, N. J., Tenenbaum, H. R., Brooks, P. J., Harrison, K. \& Sines, J. (2011). Perspective taking in children's narratives about jealousy. British Journal of Developmental Psychology, 29, 86-109.

Armon-Lotem, S., De Jong, J., \& Meir, N. (Eds.) (2015). Assessing Multilingual Children: Disentangling Bilingualism from Language Impairment. Bristol, UK: Multilingual Matters.

Bohnacker, U. (2016). Tell me a story in English or Swedish: Narrative production and comprehension in bilingual preschoolers and first graders. Applied Psycholinguistics, 37(1), 19-48.

Bruner, J. (1986). Actual minds: Possible worlds. Cambridge, MA: Harvard University Press.

Chimirala, U. M. (2017). Teacher's 'other' language preference: A study of Monolingual mindset in the classroom space. In H. Coleman (Ed.) Multilingualisms and Development (pp. 236-248). New Delhi: British Council.

Clyne, M. (2008). The monolingual mindset as an impediment to the development of plurilingual potential. Sociolinguistic Studies, 2(3), 347-366.

Cook, V. (2003). Effect of the Second Language on the First. Clevedon: Multilingual Matters.

Cummins, J. (1979). Linguistic interdependence and the educational development of bilingual children. Review of Educational Research, 49, 222-251. 
Cummins. J. (2011). Literacy engagement: Fueling academic growth for language learners. The Reading Teacher, $65(2), 142-146$.

Cummins J. (2017). BICS and CALP: Empirical and Theoretical Status of the Distinction. In: B. Street \& S. May (Eds.), Literacies and Language Education. Encyclopedia of Language and Education (3rd ed.). Springer, Cham.

Daller, M. \& Ongun, Z. (2017). The Threshold Hypothesis revisited: Bilingual lexical knowledge and nonverbal IQ development. International journal of bilingualism, 19(2), 1-20.

De Houwer, A., Bornstein, M., \& Putnick, D. (2014). A bilingual-monolingual comparison of young children's vocabulary size: Evidence from comprehension and production. Applied Psycholinguistics, 35, 11891211.

Deogaonkar, S.G. (2007). The Gonds of Vidarbha. New Delhi: Concept Publishing House.

Diaz, R. (1985). Bilingual cognitive development: Addressing three gaps in current research. Child Development, $56,1376-1388$.

Francis, N. (2000). The Shared Conceptual System and Language Processing in bilingual Children: Findings from Literacy Assessment in Spanish and Nahuatl. Applied Linguistics, 21(2), 170-204.

Gagarina, N., Klop, D., Kunnari, S., Tantele, K., Välimaa, T., Balčiūnienė, I., Bohnacker, U. \& Walters, J. (2012). MAIN: Multilingual Assessment Instrument for Narratives. ZAS Papers in Linguistics, 56, 1-140.

Gagarina, N., Klop, D., Kunnari, S., Tantele, K., Välimaa, T., Bohnacker, U. \& Walters, J. (2019). MAIN: Multilingual Assessment Instrument for Narratives - Revised. ZAS Papers in Linguistics, 63, 1-36.

Grosjean, F. (1989). Neurolinguists, beware! The bilingual is not two monolinguals in one person. Brain and Language 36(1), 3-15.

Grosjean, F. (1997). The bilingual individual. Interpreting, 2(1/2), 163-187.

Grosjean, F. (1998). Transfer and language mode. Bilingualism: Language and Cognition, 1(3), 175-176.

Gutierrez-Clellen, V.F. (2002). Narratives in two languages: Assessing performance of bilingual children. Linguistics and Education, 13(2), 175-197.

Guruge, A. W. P. (1991). The Society of the Ramayana. Abhinav Publications, India.

Hall, J. K., Cheung, A \& Carlsom, M. T. (2006). Conceptualizing Multicompetence as a Theory of Language. Applied Linguistics, 27(2), 220-240.

Hammer, C., Lawrence, F., \& Miccio, A. (2008). Exposure to English before and after entry into Head Start: Bilingual children's receptive language growth in Spanish and English. The International Journal of Bilingual Education and Bilingualism, 11, 30-56.

Hudson, J. A., \& Shapiro, L. R. (1991). Children's scripts, stories and personal narratives. In A. McCabe, \& C. Peterson (Eds.), Developing narrative structure (pp. 89-136). Hillsdale, NJ: Erlbaum.

Jessner, U. (2008). A DST-model of multilingualism and the role of metalinguistic awareness. Second language development as a dynamic process. Modern Language Journal, 92(2), 270-283.

John, S. (2017). Unleashing potential in multilingual classrooms: The case of Bastar in Chhattisgarh State, India. In H. Coleman (Ed.), Multilingualisms and Development (pp. 181-189). New Delhi: British Council.

Kunnari, S., Välimaa, T., \& Laukkanen-Nevala, P. (2016). Macrostructure in the narratives of monolingual Finnish and bilingual Finnish-Swedish children. Applied Psycholinguistics, 37(1), 123-144. 
Laakso, J., Sarhimaa, A., Spiliopoulou Å. S., \& Toivanen, R. J. (2016). Towards openly multilingual policies and practices: Assessing minority language maintenance across Europe. Bristol: Multilingual matters.

Maviş, İ., Müge, T., \& Gagarina, N. (2016). Macrostructure Components in Narrations of Turkish-German Bilingual Children. Applied Psycholinguistics, 37(1), 69-89.

Mohanty, A. K. (2018). The Multilingual Reality Living with Languages. Multilingual Matters, Bristol.

Mohanty, A.K. \& Perragaux, C. (1996). Language Acquisition and Bilingualism. In J.W. Berry, P.D. Dasen \& T.S. Saraswathi (Eds.), Handbook of Cross-cultural Psychology: Basic Processes and Human Development (pp. 217-253). Needhem Heights, MA: Allyn \& Bacon.

Muñoz-Sandoval, A. F., Cummins, J., Alvarado, C. G., \& Ruef, M. L. (1998). Bilingual Verbal Ability Tests, Comprehensive Manual. Itasca, IL: Riverside Publishing.

Natarajan, G. V. (2001). What Happens in a Linguistic Junction: Masala Chai of Multi-Ethnicity and Communication in Bastar? Languages in India, 1(3).

Otwinowska, A., Mieszkowska, K., Białecka-Pikul, M., Opacki, M., \& Haman, E. (2018). Retelling a model story improves the narratives of Polish-English bilingual children. International Journal of Bilingual Education and Bilingualism, 1-25.

Pattanayak, D.P. (1986). Study of Languages - A Report. New Delhi: NCERT.

Pearson, B. Z. (2002). Narrative Competence among Monolingual and Bilingual School Children in Miami. In D. K. Oller \& R. E. Eilers (Eds.), Language and Literacy in Bilingual Children (pp. 135-174). Clevedon: Multilingual Matters.

Pearson, B., Fernandez, S., \& Oller, K. (1993). Lexical development in bilingual infants and toddlers: Comparison to monolingual norms. Language Learning, 43, 93-120.

Rubio-Marin, R. (2007). Language Rights: Exploring the Competing Rights. In Will Kymlicka and Alan Patten (Ed) Language Rights and Political Theory (pp. 289-322). Oxford: Oxford University Press.

Sarangi, S. K. (2017). Mind the gap: 'Communicative vulnerability' and the mediation of linguistic/cultural diversity in healthcare settings. In H. Coleman (Ed.) Multilingualisms and Development. London: British Council Publications.

Schwartz, M., \& Shaul, Y. (2013). Narrative development among language-minority children: the role of bilingual versus monolingual preschool education. Language, Culture and Curriculum, 26(1), 36-51.

Setati, M., Adler, J, Reed, Y \& Bapoo, A. (2002). Incomplete journeys: Code-switching and other language practices in mathematics, science and English language classrooms in South Africa. Language and Education, 16(2), 128-149.

Severing, R., \& Verhoven, L. (2001). Bilingual narrative development in Papiamento and Dutch. In L. Verhoeven. \& S. Strömqvist (Eds.), Narrative Development in a Multilingual Context (pp. 255-276). Amsterdam: John Benjamins.

Shukla, H. L. (1992). The History of the people of Bastar: A study of tribal insurgency. Delhi: Sharada Publishing House.

Simon-Cereijido G., \& Gutierrez-Clellen, V.F. (2009). A cross-linguistic and bilingual evaluation of the interdependence between lexical and grammatical domains. Applied Psycholinguistics, 30, 315-337.

Skutnabb-Kangas, T. (2020). Linguistic genocide. A Global Crime. In M. Göçek \& F. Greenland (Eds.), Cultural Violence and Destruction of Communities: New theoretical perspectives. Routledge. 
Spolsky, B. (2019). Endangered Languages and the Evolution of Linguistic Repertoires. Radhbai Katre Memorial Lecture, delivered at ICOLSI-41, Amarkantak, Nov 13-15, 2019.

Squires, K. E., Lugo-Neris, M. J., Peña, E. D., Bedore, L. M., Bohman, T. M., \& Gillam, R. B. (2014). Story retelling by bilingual children with language impairments and typically developing controls. International journal of language \& communication disorders, 49(1), 60-74

Thordardottir, E. (2011). The relationship between bilingual exposure and vocabulary development. International Journal of Bilingualism, 15(4), 426-445.

Verhoeven, L. T. (1994). Transfer of Bilingual Development: the Linguistic Interdependence Hypothesis Revisited. Language Learning, 44(3), 381-415. 